\title{
Biochemical studies of interleukin-2, 4, 6 and 8 in patients with chronic liver and kidney diseases
}

\author{
Mohamed Ali El-Desouky ${ }^{1}$, Sanaa Osman Abd-Alaa ${ }^{2}$, Afaf Abd El-Aleem³, \\ Hala Moustafa Ahmed ${ }^{4}$, Hazem Mohamed El- Hariri ${ }^{5}$ and Hend Gaber Badawy ${ }^{6}$ \\ ${ }^{I}$ Associate professor of Biochemistry Faculty of Science Cairo University \\ ${ }^{2}$ Professor of Organic Chemistry Faculty of Science Cairo University \\ ${ }^{3}$ Professor of Clinical \& Chemical Pathology, Faculty of Medicine, Ain Shams University \\ ${ }^{4}$ Associate Professor Dept.of Technology Equipment Faculty of Applied Medical Science October 6 University \\ ${ }^{5}$ Assistant researcher of Community medicine, National research center \\ ${ }^{6}$ ph.D, Faculty of Science - Cairo University
}

\begin{abstract}
Background: Interleukins are a group of cytokines (secreted proteins/signaling molecules) that were first seen to be expressed by white blood cells (leukocytes). In chronic hepatitis $C$, intra-hepatic expression of both IL-8 and IL-2 increased with fibrosis and inflammatory activity. Positive correlations were found between IL-8 and other cytokines and between cytokines themselves. These findings suggest that these interacting cytokines play an active role in the pathogenesis of $\mathrm{CHC}$, and maybe involved in the up regulation or induction of one and other, and interleukin-6 (IL-6), the major cytokine inducers of the acute phase response, are markedly raised in acute alcoholic hepatitis and correlate closely with clinical and laboratory indicators of disease severity.

Methods: We measured (IL-2, IL-4, IL-6 and IL-8) serum levels in 60 patients classified into three different groups twenty chronic renal failure patients, twenty liver disease patients and twenty patients of chronic renal failure combined with liver diseases in comparison to twenty healthy controls. Serum (IL-2, IL-4, IL-6 and IL-8) were determined using ELISA technique.

Results: IL-2 and IL-6 were significantly highest in HCV and combined groups with no significant difference between them, followed by renal group compared to IL-4 and IL-8 were significantly highest in combined group, followed by renal group, followed by HCV group and lowest in control group.

Conclusions: IL-2 and IL-6 are elevated in patients with chronic HCV disease. IL-4 and IL-8 are elevated in chronic renal failure.
\end{abstract}

Keywords: Chronic HCV; Chronic renal failure; Interleukins

\section{Introduction}

IL-2 is necessary for the growth, proliferation, and differentiation of T cells to become 'effector' $\mathrm{T}$ cells. IL-2 is normally produced by T cells during an immune response. Antigen binding to the T cell receptor (TCR) stimulates the secretion of IL-2, and the expression of IL-2 receptors IL-2R. The IL-2/IL-2R interaction then stimulates the growth, differentiation and survival of antigen-specific CD4+ T cells and CD8+ T cells [1]. As such, IL-2 is necessary for the development of T cell immunologic memory, which depends upon the expansion of the number and function of antigen-selected T cell clones.IL-2 is also necessary during T cell development in the thymus for the maturation of a subset of T cells that are termed regulatory T cells (T-regs) [2].

Interleukin-4, is a cytokine that induces differentiation of naive helper T cells (Th0 cells) to Th2 cells. Upon activation by IL-4, Th2 cells subsequently produce additional IL-4. The cell that initially produces IL-4, thus inducing Th0 differentiation, has not been identified, but recent studies suggest that basophils may be the effector cell [3]. It has many biological roles, including the stimulation of activated B-cell and T-cell proliferation, and the differentiation of B cells into plasma cells. It is a key regulator in humoral and adaptive immunity. IL-4 induces B-cell class switching to IgE, and up-regulates MHC class II production. IL-4 decreases the production of Th1 cells, macrophages, IFN-gamma, and dendritic cell IL-12. Overproduction of IL-4 is associated with allergies [4]. Tissue macrophages play an important role in chronic inflammation and wound repair. The presence of IL-4 in extravascular tissues promotes alternative activation of macrophages into M2 cells and inhibits classical activation of macrophages into M1 cells. An increase in repair macrophages (M2) is coupled with secretion of IL-10 that results in a diminution of pathological inflammation. Release of arginase, proline and polyaminases by the activated M2 cell is tied with wound repair and fibrosis [5].

Interleukin-6 (IL-6) is an interleukin that acts as both a pro-inflammatory cytokine and an antiinflammatory myokine. In humans, it is encoded by the IL-6 gene. IL-6 is secreted by T cells and macrophages to stimulate immune response, e.g. during infection and after trauma, especially burns or other tissue damage 
leading to inflammation. IL-6 also plays a role in fighting infection, as IL-6 has been shown in mice to be required for resistance against bacterium Streptococcus pneumonia [6]. IL-6 is an important mediator of fever and of the acute phase response. It is capable of crossing the blood-brain barrier and changing the body's temperature set point. In muscle and fatty tissue, IL-6 stimulates energy mobilization that leads to increased body temperature. IL- 6 can be secreted by macrophages in response to specific microbial molecules, referred to as pathogen-associated molecular patterns (PAMPs). These PAMPs binding to an important group of detection molecules of the innate immune system, called pattern recognition receptors (PRRs), including Toll-like receptors (TLRs). These are present on the cell surface and intracellular compartments and induce intracellular signaling cascades that give rise to inflammatory cytokine production [7]. IL-6 is also essential for hybridoma growth and is found in many supplemental cloning media such as briclone. Inhibitors of IL-6 (including estrogen) are used to treat postmenopausal osteoporosis. IL-6 is also produced by adipocytes and is thought to be a reason why obese individuals have higher endogeneous levels of CRP. Intranasally administered IL-6 has been shown to improve sleep-associated consolidation of emotional memories [8]. IL-6 is responsible for stimulating acute phase protein synthesis, as well as the production of neutrophils in the bone marrow. It supports the growth of $\mathrm{B}$ cells and is antagonistic to regulatory $\mathrm{T}$ cells.

Interleukin-8 (IL-8) is a chemokine produced by macrophages and other cell types such as epithelial cells, airway smooth muscle cells and endothelial cells. Endothelial cells store IL-8 in their storage vesicles, the Weibel-Palade bodies. In humans, the interleukin-8 protein is encoded by the IL-8 gene [9]. There are many receptors on the surface membrane capable of binding IL-8; the most frequently studied types are the G proteincoupled serpentine receptors CXCR1 and CXCR2. Expression and affinity for IL-8 differs between the two receptors $($ CXCR1 > CXCR2). Toll-like receptors are the receptors of the innate immune system. These receptors recognize antigen patterns (like LPS in gram negative bacteria). Through a chain of biochemical reactions, IL- 8 is secreted and is an important mediator of the immune reaction in the innate immune system response. IL-8, also known as neutrophil chemotactic factor, has two primary functions. It induces chemotaxis in target cells, primarily neutrophils but also other granulocytes, causing them to migrate toward the site of infection. IL-8 also induces phagocytosis once they have arrived. IL-8 is also known to be a potent promoter of angiogenesis. In target cells, IL-8 induces a series of physiological responses required for migration and phagocytosis, such as increases in intracellular $\mathrm{Ca}^{2+}$, exocytosis (e.g. histamine release), and the respiratory burst [10].

\section{Aim of the work}

Biochemical utility of interleukins (IL-2), (IL-4), (IL-6) and (IL-8) as a marker in chronic renal diseases alone, liver diseases alone and also in chronic renal diseases combined with liver diseases. In addition some biochemical parameters, such as urea, creatinine, AST, ALT, Uric acid, albumin and glucose level, will be analyzed.

\section{Materials \& methods}

Group (1) included twenty healthy normal subjects (11 males \& 9 females), they were studied as control group. Sixty patients who approved (signed informed written consent) to share in the study through Three groups:, Group (2) consisted of twenty chronic renal failure patients included (11 males \& 9 females) who were on periodic heamodialysis three times per week,

Group (3) consisted of twenty chronic HCV patients (10 males \& 10 females) and

Group (4) included twenty chronic renal failures combined with chronic HCV disease patients (combined group), (10 males \& 10 females).

\section{Blood samples collection}

Blood sample were collected from all subjects drawn after an overnight fast of at least 8 hours and for subjects which undergo heamodialysis the samples were drawn before the heamodialysis using a $10 \mathrm{ml}$ disposable syringe. About $8 \mathrm{ml}$ of blood were added to vacutainer plane tubes, the blood was left for about 10 minutes to allow blood to clot then, serum samples were obtained by centrifugation at (2000 rpm for 10 minutes). Serum samples were divided into two aliquots one for biochemical analysis and the other which stored at $\leq-20^{\circ} \mathrm{C}$ for cytokines.

Routine laboratory investigations (Liver function tests as (ALT, AST, and serum albumin), Kidney function tests as (urea, creatinine and uric acid), Fasting Blood Sugar) were determined using standard kits.

Cytokines Interleukin-2, Interleukin-4, Interleukin-6 and Interleukin-8 were determined using ELISA kit [11, 12, 13 and 14]. This assay employs the quantitative sandwich enzyme immunoassay technique. Polyclonal antibody specific for interleukins have been pre-coated onto a microplates. Standards and samples were pipette into the wells and any interleukins present were pounded by the immobilized antibody. After washing away any unbounded substances, an enzyme-linked polyclonal antibody specific for interleukins were added to wells. 
Following a wash to remove any unbounded antibody-enzyme reagent, a substrate solution was added to the wells and color develops in proportion to the amount of interleukins bound in the initial step. The color development was stopped and the intensity of the color was measured.

\section{Statistical methods}

The collected data were coded, tabulated, and statistically analyzed using SPSS program (Statistical Package for Social Sciences) software version 18.0. Descriptive statistics were done for the quantitative parametric data as mean $\pm \mathrm{SD}$ (standard deviation) and minimum\& maximum of the range, while they were done for qualitative data as number and percentage. Inferential analyses were done for quantitative variables using independent $\mathrm{t}$-test in cases of two independent groups, ANOVA test with post hoc LSD for more than two independent groups. In qualitative data, inferential analyses for independent variables were done using Chi square test for differences between proportions, while correlations were done using Pearson Correlation. The level of significance was taken at $\mathrm{P}$ value $<0.050$ is significant, otherwise is non-significant.

\section{Results}

The four studying groups were matched for age and sex. Chronic Renal group and combined group were homogenous for Duration of renal disease.

IL-2 and 6 were significantly highest in chronic HCV and combined groups with no significant difference between them, followed by renal group and lowest in control group. IL-4 and 8 were significantly highest in combined group, followed by renal group, followed by HCV group and lowest in control group. ALT and AST were significantly highest in HCV and combined groups and lowest in control and renal groups with no significant difference between them. Albumin was significantly highest in control groups with no significant difference between other groups. Urea, creatinine and uric acid were significantly highest in renal and combined groups with no significant difference between them, followed by HCV and control groups. Fasting was significantly highest in HCV and combined groups than control and renal groups (Table 1). In combined group there was a significant positive correlation between Interleukin-2 and creatinine in combined group (Table 2).

Table (1): Control subjects and patients.

\begin{tabular}{|c|c|c|c|c|c|}
\hline & Control group & $\begin{array}{l}\text { Chronic Renal } \\
\text { group }\end{array}$ & $\begin{array}{l}\text { Chronic HCV } \\
\text { group }\end{array}$ & Combined group & $\mathbf{P}$ \\
\hline \multicolumn{6}{|c|}{ Mean \pm SD } \\
\hline $\mathbf{N}$ & 20 & 20 & 20 & 20 & \\
\hline Age (years) & $38.9 \pm 4.3$ & $38.5 \pm 4.3$ & $38.7 \pm 4.4$ & $38.6 \pm 4.6$ & $*>0.050$ \\
\hline $\begin{array}{l}\text { Sex (Male) } \\
\text { n (\%) }\end{array}$ & $11(55.0 \%)$ & $11(55.0 \%)$ & $10(50.0 \%)$ & $10(50.0 \%)$ & $\wedge>0.050$ \\
\hline $\begin{array}{l}\text { Duration of renal disease } \\
\text { (days) }\end{array}$ & & $3.2 \pm 0.6$ & & $3.0 \pm 0.7$ & $\#>0.050$ \\
\hline $\begin{array}{l}\text { Duration of liver disease } \\
\text { (days) }\end{array}$ & & & $3.8 \pm 0.8$ & $4.2 \pm 0.8$ & $\#>0.050$ \\
\hline IL-2 (pg/ml) & $9.4 \pm 0.6 \mathrm{a}$ & $27.4 \pm 4.7 \mathrm{~b}$ & $102.3 \pm 6.3 \mathrm{c}$ & $104.2 \pm 5.2 \mathrm{c}$ & $*<0.001$ \\
\hline IL-4 (pg/ml) & $13.4 \pm 2.6 \mathrm{a}$ & $100.5 \pm 6.9 b$ & $37.3 \pm 7.1 \mathrm{c}$ & $121.9 \pm 14.6 \mathrm{~d}$ & $*<0.001$ \\
\hline IL-6 (pg/ml) & $20.3 \pm 3.9 a$ & $38.8 \pm 6.9 \mathrm{~b}$ & $98.6 \pm 7.0 \mathrm{c}$ & $103.1 \pm 4.7 \mathrm{c}$ & $*<0.001$ \\
\hline IL-8 (pg/ml) & $25.7 \pm 4.3 \mathrm{a}$ & $103.4 \pm 8.7 \mathrm{~b}$ & $43.4 \pm 8.7 \mathrm{c}$ & $130.3 \pm 8.6 \mathrm{~d}$ & $*<0.001$ \\
\hline $\operatorname{ALT}(\mathbf{U} / \mathbf{L})$ & $18.7 \pm 4.4 \mathrm{a}$ & $13.2 \pm 4.1 \mathrm{~b}$ & $252.9 \pm 14.1 \mathrm{c}$ & $256.5 \pm 6.1 \mathrm{c}$ & $*<0.001$ \\
\hline$\overline{\operatorname{AST}}(\mathrm{U} / \mathrm{L})$ & $19.4 \pm 4.3 \mathrm{a}$ & $18.2 \pm 5.6 \mathrm{a}$ & $80.0 \pm 8.9 \mathrm{~b}$ & $57.6 \pm 6.4 \mathrm{~b}$ & $*<0.001$ \\
\hline Albumin (g/dl) & $4.2 \pm 0.5 \mathrm{a}$ & $2.9 \pm 0.3 \mathrm{~b}$ & $3.0 \pm 0.3 \mathrm{~b}$ & $2.9 \pm 0.3 b$ & $*<0.001$ \\
\hline Urea (mg\%) & $39.5 \pm 6.8 \mathrm{a}$ & $105.5 \pm 9.0 \mathrm{~b}$ & $43.9 \pm 2.8 \mathrm{a}$ & $108.0 \pm 9.4 \mathrm{~b}$ & $*<0.001$ \\
\hline Creatinine (mg\%) & $0.5 \pm 0.3 \mathrm{a}$ & $7.3 \pm 0.9 \mathrm{~b}$ & $0.7 \pm 0.3 \mathrm{a}$ & $7.3 \pm 1.3 \mathrm{~b}$ & $*<0.001$ \\
\hline Uric Acid (mg/dl) & $3.6 \pm 0.4 \mathrm{a}$ & $6.2 \pm 0.5 \mathrm{~b}$ & $4.0 \pm 0.7 \mathrm{c}$ & $6.5 \pm 0.6 \mathrm{~b}$ & $*<0.001$ \\
\hline Fasting glucose (mg/dl) & $95.4 \pm 10.4 \mathrm{a}$ & $100.6 \pm 6.9 \mathrm{a}$ & $114.3 \pm 9.3 b$ & $111.7 \pm 9.2 b$ & $*<0.001$ \\
\hline
\end{tabular}

IL: Interleukin, ALT: Alanine transaminase, AST: Aspartate transaminase, ${ }^{*}$ ANOVA, \#Independent t-test, ${ }^{\wedge} \mathrm{Chi}$ square test

Homogenous groups labeled as a, b, c and d upon post hoc LSD test 
Table (2): Correlation between Interleukins and laboratory findings

\begin{tabular}{|c|c|c|c|c|c|c|c|c|}
\hline & \multicolumn{2}{|c|}{ IL-2 } & \multicolumn{2}{|c|}{ IL-4 } & \multicolumn{2}{|c|}{ IL-6 } & \multicolumn{2}{|c|}{ IL-8 } \\
\hline & $\mathbf{r}$ & p & $\mathbf{r}$ & $\mathbf{p}$ & $\mathbf{r}$ & $\mathbf{p}$ & $\mathbf{r}$ & p \\
\hline & \multicolumn{8}{|c|}{ Chronic Renal group } \\
\hline Urea & 0.311 & 0.181 & 0.292 & 0.212 & 0.364 & 0.114 & -0.031 & 0.898 \\
\hline Creatinine & 0.186 & 0.433 & 0.152 & 0.523 & -0.147 & 0.536 & 0.171 & 0.470 \\
\hline \multirow[t]{2}{*}{ UA } & 0.048 & 0.840 & 0.016 & 0.947 & -0.313 & 0.180 & 0.199 & 0.400 \\
\hline & \multicolumn{8}{|c|}{ Chronic HCV group } \\
\hline $\mathbf{A L T}$ & 0.039 & 0.870 & -0.096 & 0.688 & 0.009 & 0.969 & -0.198 & 0.402 \\
\hline AST & -0.113 & 0.636 & 0.046 & 0.846 & -0.135 & 0.569 & 0.046 & 0.848 \\
\hline \multirow[t]{2}{*}{ Albumin } & -0.059 & 0.806 & 0.003 & 0.99 & -0.285 & 0.224 & 0.102 & 0.669 \\
\hline & \multicolumn{8}{|c|}{ Combined group } \\
\hline ALT & -0.036 & 0.882 & -0.312 & 0.180 & -0.323 & 0.165 & 0.200 & 0.397 \\
\hline$\overline{\text { AST }}$ & -0.170 & 0.474 & -0.438 & 0.053 & -0.160 & 0.501 & -0.293 & 0.210 \\
\hline Albumin & -0.248 & 0.291 & -0.014 & 0.952 & 0.193 & 0.415 & -0.146 & 0.538 \\
\hline Urea & -0.238 & 0.311 & -0.171 & 0.470 & -0.025 & 0.916 & 0.061 & 0.797 \\
\hline Creatinine & 0.502 & 0.024 & -0.033 & 0.891 & 0.109 & 0.647 & -0.064 & 0.787 \\
\hline UA & 0.078 & 0.744 & -0.312 & 0.180 & -0.107 & 0.654 & 0.037 & 0.877 \\
\hline
\end{tabular}

\section{Discussion}

IL-2 is necessary for the growth, proliferation, and differentiation of T cells to become 'effector' T cells. IL-2 is normally produced by T cells during an immune response. Antigen binding to the T cell receptor (TCR) stimulates the secretion of IL-2, and the expression of IL-2 receptors IL-2R. The IL-2/IL-2R interaction then stimulates the growth, differentiation and survival of antigen-specific CD4+ T cells and CD8+ T cells [15].

Interleukin-6 (IL-6) is an interleukin that acts as both a pro-inflammatory cytokine and an antiinflammatory myokine. In humans, it is encoded by the IL-6 gene. IL-6 is secreted by T cells and macrophages to stimulate immune response, e.g. during infection and after trauma, especially burns or other tissue damage leading to inflammation [16].

The present study showed that the level of serum interleukin- 2 and interleukin- 6 were significantly highest in HCV and combined groups with no significant difference between them, followed by renal group and lowest in control group. The high increased level in case of HCV due to circulating inflammatory cells, especially from the monocyte lineage. These indicate that sIL-2R might be a potential marker for immune cell activation in CLD, especially for proinflammatory and profibrogenic non-classical CD14+CD16+ monocytes. This explanation mentioned by [17].

Elevated plasma IL-6 levels in ESRD patients may be related to (i) the loss of kidney function, (ii) uraemia per se (and its sequelae, such as fluid overload, oxidative stress and susceptibility to infections) and (iii) dialysis-related factors. Even before the initiation of dialysis therapy, patients with decreased renal function already demonstrated signs of inflammation and the deterioration of renal function has been associated with a significant increase in serum cytokine levels. This explanation mentioned by [18].

The present study was in agreement with [19] they pointed to an increased serum interleukin-2 in infection with hepatitis $\mathrm{C}$ virus and had demonstrated that hepatocytes represent the principal source of the cytokine in HCV in vivo infection. Mitochondrial localization of IL-2 suggested a direct involvement of the cytokine in disturbed function of the organelles.

Also the present study was in agreement with [20] they found that the plasma levels of sIL-2Ra were predictive of long-term renal disease progression in a large cohort of patients with biopsy-proven IgAN. Further studies were warranted to evaluate if sIL-2Ra levels feasibly contributed in the monitoring of effects of treatment, aimed to prevent the progression of interstitial fibrosis and progressive glomerulosclerosis in IgAN.

[21] analyzed the serum IL-2 in patients with renal failure and reported that sIL2-Ra levels were significantly higher in patients than in controls $(\mathrm{P}<0.001)$. sIL-2Ra levels in the upper third tertile predicted a severe renal outcome, even after adjustment for the main clinical risk factors: time average albuminuria and GFR at baseline (Relative risk 5.35, P $<0.001$ ). sIL-2Ra levels also correlated significantly to the yearly GFR slope $(\beta=-0.24, \mathrm{P}=0.01)$.

Our experimental IL-6 results are in agreement with the study of [22] who reported that The experiments indicate an involvement of IL-6 in the pathogenesis of liver diseases and suggest a protective role of IL-6/gp130-dependent pathways in nonparenchymal liver cells during fibrosis progression in chronic liver diseases.

IL-4 is a cytokine that induces differentiation of naive helper T cells (Th0 cells) to Th2 cells. Upon activation by IL-4, Th2 cells subsequently produce additional IL-4. The cell that initially produces IL-4, thus inducing Th 0 differentiation, has not been identified, but recent studies suggest that basophils may be the effector cell [23]. 
Interleukin-8 (IL-8) is a chemokine produced by macrophages and other cell types such as epithelial cells, airway smooth muscle cells and endothelial cells. Endothelial cells store IL-8 in their storage vesicles, the Weibel-Palade bodies. In humans, the interleukin-8 protein is encoded by the IL-8 gene [24].

The present study showed that the serum level of interleukin- 4 and interleukin- 8 were significantly highest in combined group, followed by renal group, and followed by HCV group and lowest in control group. Because during a hemodialysis session, cytokines were released mainly by monocytes activated by endotoxintype compounds in dialyzer fluid, complement factors and direct contact with dialyzer membrane. So they highly increased in case of heamodialysis patients. This explanation mentioned by [25].

In case of HCV patients IL-8 are elevated this elevation, due to the elevation of Th2 cytokine levels may represent a systemic response and not a result of increased local production within the liver [26].

Our experimental IL-4 results are in agreement with the study of [27] who reported that higher levels of circulating proinflammatory cytokines (IL-2, IL-4, IL-5, IL-12, T-cell number and function) were associated with mortality, while immune parameters reflecting improved T-cell function were associated with survival in ESRD patients treated with HD, independent of other medical risk factors. These factors may serve as markers for outcome. The mechanism underlying the relationship of immune function and survival, and the effect of interventions to normalize immune function in HD patients should be studied.

On the other hand in case of liver diseases [28] found that one striking clinical feature of hepatitis $\mathrm{C}$ virus $(\mathrm{HCV})$ infection was that more than $50 \%$ of patients with acute hepatitis $\mathrm{C}$ will develop chronic infection. They examined the activation of type 2-like T-helper (Th2-like) cells relating to the development of chronicity. Peripheral blood CD4+ T-cell proliferation and cytokine secreation in response to a panel of recombinant HCV antigens including core (C22), envelope 1 (E1), E2, nonstructural (NS) protein 4 (C100), fusion protein of NS3 and NS4 (C200), and NS5 were assayed in patients with acute hepatitis C.IL-4 and IL-10 (Th2 responses) were detectable, and C22-spicific Th2-like T-cell clones could be generated from patients with chronicity. So that activation of $\mathrm{Th} 2$ responses in acute hepatitis $\mathrm{C}$ patients may play a role in the development of chronicity.

Our experimental IL-8 results are in agreement with the study of [29] he found that serum IL-8 levels were higher in patients with HCV compared with control subjects, and in patients with HCC associated with $\mathrm{HCV}$ infection compared with control subjects. They found also that serum level of IL-8 is significantly higher in patients of chronic hepatitis $\mathrm{C}$ with HCC than patients of chronic hepatitis $\mathrm{C}$ without HCC.

From Other hand in case in chronic renal failure patients [30] Found that the serum concentration of IL-8 was significantly higher in the HD patients before and after dialysis than in the controls.

The patients with chronic renal failure commonly present with abnormalities of immune function related with impaired kidney function and the accumulation of uremic toxins in addition to bioincompatibility of dialyzer membranes.

\title{
V. Conclusion
}

IL-2 and IL-6 are elevated in patients with chronic HCV disease. IL-4 and IL-8 are elevated in chronic renal failure.

\author{
Abbreviations \\ $\mathrm{IL}=$ Interleukine; $\mathrm{CLD}=$ Chronic liver diseases; $\mathrm{TCR}=\mathrm{Tcell}$ receptor; $\mathrm{T}$-regs $=$ Regulatory $\mathrm{T}$ cells; PAMPs $=$ \\ Pathogen-associated molecular patterns; PRRs $=$ Pattern recognition receptors; TLRs $=$ Toll-like receptors; $\mathrm{SD}=$ \\ Standard deviation; $\mathrm{HCV}=$ Hepatitis $\mathrm{C}$ virus; $\mathrm{GFR}=$ Glomerular filtration rate; $\mathrm{HD}=$ Hemodialysis; sIL-2R= \\ soluble interleukin-2 receptor.
}

\section{References}

[1]. Beadling C, Smith KA (November 2002). "DNA array analysis of interleukin-2-regulated immediate/early genes". Med Immunol 1 (1): 2. doi:10.1186/1476-9433-1-2. PMC 149405.

[2]. Thornton AM, Donovan EE, Piccirillo CA, Shevach EM (June 2004). "Cutting edge: IL-2 is critically required for the in vitro activation of CD4+CD25+ T cell suppressor function". J. Immunol. 172 (11): 6519-23.

[3]. Sokol CL, Barton G, Farr AG and Medzhitov R, (2008). "A mechanism for the initiation of allergen-induced T helper type 2 responses". Nat Immunol 9 (3): 310-318.

[4]. Jon Aster, Vinay Kumar, Abul K. Abbas; Nelson Fausto (2009). Robbins \& Cotran Pathologic Basis of Disease (8th ed.). Philadelphia: Saunders. p. 54.

[5]. Marone G, Florio G, Petraroli A, de Paulis A (2001). "Dysregulation of the IgE/Fc epsilon RI network in HIV-1 infection". J. Allergy Clin. Immunol. 107 (1): 22-30.

[6]. Febbraio MA, Pedersen BK (2005). "Contraction-induced myokine production and release: is skeletal muscle an endocrine organ?". Exerc Sport Sci Rev 33 (3): 114-119.

[7]. Pedersen BK, Febbraio MA (October 2008). "Muscle as an endocrine organ: focus on muscle-derived interleukin-6". Physiol. Rev. 88 (4): 1379-406.

[8]. Benedict C, Scheller J, Rose-John S, Born J, Marshall L (October 2009). "Enhancing influence of intranasal interleukin-6 on slow-wave activity and memory consolidation during sleep". FASEB J. 23 (10): 3629-3636.

[9]. Hedges JC, Singer CA, Gerthoffer WT (July 2000). "Mitogen-activated protein kinases regulate cytokine gene expression in human airway myocytes". Am. J. Respir. Cell Mol. Biol. 23 (1): 86-94. 
[10]. Rottner, Mathilde; Freyssinet, Martinez (2009). "Mechanisms of the noxious inflammatory cycle in cystic fibrosis". Respiratory Research 10: 1-11.

[11]. Maccio A, Lai P, Santona MC, Pagliara L, Melis GB, Mantovani G. (1998). High serum levels of soluble IL-2 receptor, cytokines, and $\mathrm{C}$ reactive protein correlate with impairment of $\mathrm{T}$ cell response in patients with advanced epithelial ovarian cancer.Gynecol Oncol. 1998;69:248-52.

[12]. Brown M., J. Hu-Li, and W. E. Paul. (1988) IL-4/B cell stimulatory factor-1 stimulates T cell growth by an IL-2 independent mechanism. J. Immunol. 1988;141: 504-511.

[13]. Geva, E., et al. (1997). Elevated levels of interleukin-6 in the follicular fluid at the time of oocyte retrieval for in vitro fertilization may predict the development of early-form ovarian hyperstimulation syndrome. Fertil. Steril. 68, 133-137.

[14]. Baggiolini M. et al. (1989) Neutrophil-activating peptide-1/Interleukin-8, a novel cytokine that activates neutrophils. J. Clin. Invest. 84:1045-1049.

[15]. Beadling C, Smith KA (November 2002). "DNA array analysis of interleukin-2-regulated immediate/early genes". Med Immunol 1 (1): 2. doi:10.1186/1476-9433-1-2. PMC 149405.

[16]. Febbraio MA, Pedersen BK (2005). "Contraction-induced myokine production and release: is skeletal muscle an endocrine organ?". Exerc Sport Sci Rev 33 (3): 114-119.

[17]. Seidler S, Zimmermann HW, Weiskirchen R, Trautwein C, Tacke F. (2012). "Elevated circulating soluble interleukin-2 receptor in patients with chronic liver diseases is associated with non-classical monocytes." 2012 Apr 24;12:38.

[18]. Bolton CH, Downs LG, Victory JG et al (2001). "Endothelial dysfunction in chronic renal failure: roles of lipoprotein oxidation and pro-inflammatory cytokines". Nephrol Dial Transplant 2001; 16:1189-1197.

[19]. Kasprzak A, Seidel J, Adamek A, Biczysko W, Wysocki J, Spachacz R, Juszczyk J and Zabel M (2006). "Interleukin-2 (IL-2) expression in livers of patients with chronic hepatitis C virus (HCV) infection". 2006;44(2):103-10.

[20]. Sigrid Lundberg, Joachim Lundahl, Iva Gunnarsson, Birgitta Sundelin and Stefan H. Jacobson (2011).” Soluble interleukin-2 receptor alfa predicts renal outcome in IgA nephropathy”. August 19, 2011. Nephrology Dialysis Transplantation, Volume 27, Issue 5Pp. 1916-1923.

[21]. Joachim Lundahl, Iva Gunnarsson, Birgitta Sundelin and Stefan H. Jacobson (2012). Nephrol. Dial. Transplant. 27 (5): 19161923. doi: 10.1093/ndt/gfr554 First published online: September 22, 2011 PMCID: PMC1535987.

[22]. Streetz KL, Tacke F, Leifeld L, Wüstefeld T, Graw A, Klein C, Kamino K, Spengler U, Kreipe H, Kubicka S, Müller W, Manns MP, Trautwein C (2003). Department of Gastroenterology, Hepatology and Endocrinology, Medizinische Hochschule Hannover, Hannover, Germany. Hepatology. Jul;38(1):218-29.

[23]. Sokol CL, Barton GM, Farr AG and Medzhitov R. (2008)"A mechanism for the initiation of allergen-induced T helper type 2 responses". Nat Immunol 9 (3): 310-318.

[24]. Hedges JC, Singer CA, Gerthoffer WT (July 2000). "Mitogen-activated protein kinases regulate cytokine gene expression in human airway myocytes". Am. J. Respir. Cell Mol. Biol. 23 (1): 86-94.

[25]. Rysz J, Banach M, Cialkowska-Rysz A, Stolarek R, Barylski M, Drozdz J and Okonski P (2006). "Blood serum levels of IL-2, IL-6, IL-8, TNF-alpha and IL-1 beta in patients on maintenance hemodialysis". 2006 Apr,3(2):151-4.

[26]. Markus Reiser, Constantine G. Marousis, David R. Nelson, Georg Lauer, Regino P. González-Peralta, Gary L. Davis, Johnson Y.N. Lau." Serum interleukin 4 and interleukin 10 levels in patients with chronic hepatitis C virus infection”. March 6, 1996; Received in revised form: July 31, 1996; Accepted: August 23, 1996.

[27]. Paul L Kimmel, Terry M Phillips, Samuel J Simmens, Rolf A Peterson, Karen L Weihs, Sylvan Alleyne, Illuminado Cruz, Jack A Yanovski and Judith H Veis (1998). "Immunologic function and survival in hemodialysis patients". (1998) 54, $236-244$.

[28]. S Tsai, Y Liaw, M Chen, C Huang and GC Kuo (2003). "Detection of type 2-like T-helper cells in hepatitis c virus infection: Implications for hepatitis C virus chronicity". Hepatology, 25: 449-458.

[29]. Hany Elewa, Manal Abd-Elmeneem, Ahmed Murad Hashem, Aml Alshehaby (2010). International Journal of Hepatology > Vol 1, No 3 (2010)> Elewa.

[30]. Bożena Polańska1, Daria Augustyniak, Irena Makulska, Maria Niemczuk, Danuta Zwolińska and Adam Jankowski1 (2010). Article first published online: 6 MAY 2010 DOI: 10.1111/j.1442-200X.2010.03162. 